doi:10.1017/\$1041610221000636

\section{Predictors of sedative-hypnotic usage among residents of old age home in northern India*}

\section{Introduction}

Sedative-hypnotics of barbiturates, older benzodiazepines, are drugs having high addiction potential (Glass et al., 2005), though provide improvement in sleep, but adverse effects are significant including risk of falls and cognitive impairment especially on long-term usage (Andrade, 2018). To subvert some of the adverse effects of benzodiazepine class sedatives, ' $z$ ' class drugs were introduced.

Since the studies on adverse and unwanted (Reeve et al., 2017) effects during long-term administration of the same in older adults are sparse, a study was planned to assess the predictors of sedative-hypnotics usage in community dwelling senior citizens admitted in leading old age home in northern India. A cross-sectional medication adherence survey was conducted using a semi-structured questionnaire in northern India to assess the prevalence of sedative-hypnotic usage among older adults residing in resident home.

The study enrolled 104 subjects out of which 15 (14.4\%) subjects, 8 males and 7 females $(\mathrm{M}: \mathrm{F}=8: 7$; mean age $=64.56 \pm 3.5$ years), used sedative-hypnotics (mean duration of use $=7.47 \pm 5.24$ years). Written and informed consent was taken from all study participants. Patients had diagnosis of Generalized Anxiety Disorder $(n=5)$, osteoarthritis $(n=3)$, cervical spondylosis $(n=3)$, chronic low back ache $(n=2)$, and rheumatoid arthritis $(n=2)$. One male older adult had comorbid diagnosis of trigeminal neuralgia, and another older adult woman had generalized epilepsy. The most common drugs used were alprazolam $(n=6)$, zolpidem $(n=3)$, zaleplon $(n=2)$, chlordiazepoxide $(n=2)$, and phenobarbitone $(n=2)$.

Out of the 15 cases who were using sedatives/ hypnotics, 8 were physician-prescribed sedativehypnotics, while rest $(n=7)$ used them on selfprescribed basis. Mean duration of usage was $7 \pm 1.5$ years, and all patients felt that they found it difficult to discontinue the medications on their own and need clinical detoxification. A total of 3

*Vikas Dhikav's affiliation has been corrected. A corrigendum detailing this change has also been published (doi:10.1017/S1041610221001022). experienced adverse reactions (3/15) such as dizziness $(n=1)$ in study period, and 2 had a history of falls in bathroom.

Naranjo Algorithm, which is the standard tool for causality assessment related to adverse drug reactions, was applied to see the causality assessment, and it was found to be 'possible' in the first case and 'probable' in other two. The study highlights the need of checking unsupervised prescription of sedative-hypnotics and underscores the importance of regular prescription review.

\section{Discussion}

Use of sedative-hypnotics in older adults is common and so are the associated adverse effects. The current study reports a high-frequency $(14.4 \%)$ sedative-hypnotic usage among older adults admitted to a senior citizen home. Though the sample size is limited, the current study describes the extent of problem in senior citizens. Since withdrawal is possible, clinical management is recommended for detoxification. Despite the available evidence that the long-term unsupervised benzodiazepines/ sedative-hypnotic usage in older adults is not appropriate, their prescription is widespread (Airagnes et al., 2016).

Comorbidities are common risk factors for benzodiazepine usage. An outpatient-based study (Satheesh et al., 2020) done in younger patients showed a prevalence of benzodiazepine abuse as $8 \%$ in India, but data in older adults are not available. A study from India (Deshpande and Nagpal, 1993) suggested that guidelines need to be developed regarding their usage to reduce their unscrupulous usage.

Several possible reasons could be responsible for high-frequency usage of sedative-hypnotics. These include limited outreach of senior citizens residing in elder care homes to specialists, overlooking/poor prescription review by general practitioners of the patients' prescriptions, and inadvertent use of repeat prescriptions.

Considering the implications of regular and unscrupulous usage of sedatives-hypnotics in older adult population viz falls, memory alterations, dizziness, hangover, accidents, etc., a larger study with the objective of studying prevalence, predictors, and causality (Naranjo et al., 1981) of sedatives/hypnotics usage in older adults is proposed. This may help avoid the drawbacks of unsupervised use associated 
with the use of sedatives and hypnotics in older adults. Also, though about half of the patients $(n=7)$ used medications on self-prescribed basis, tight regulations about the availability of these 'prescription only' medications need to be maintained. Also, reducing the use of unnecessary drugs (polypharmacy) that have potential to harm may help reinforce the use of drugs that have potential to prevent cardiovascular issues (Dhikav et al., 2013) in older adults as total number of drugs used may be curbed.

\section{Conflict of interest}

None.

\section{Description of authors' roles}

1. Vikas Dhikav conceptualized, designed, written manuscript, supervised Ms Chang during her Masters of Science (Toxicology) thesis, analyzed, interpreted data, edited the manuscript for final publication, and did revision of manuscript.

2. Sangtitula Chang, Masters in Science Student, collected data under direct supervision of Dr Vikas Dhikav.

3. Sonia Mor, $\mathrm{PhD}$, did proof reading of the manuscript and editorial corrections for final publication.

\section{References}

Airagnes, G., Pelissolo, A., Lavallée, M., Flament, M. and Limosin, F. (2016). Benzodiazepine misuse in the older adults: risk factors, consequences, and management. Current Psychiatry Reports, 1, 89.

Andrade, C. (2018). Sedative hypnotics and the risk of falls and fractures in the older adults. The fournal of Clinical Psychiatry, 79, 3, 18.
Deshpande, S. N. and Nagpal, R. S. (1993).

Benzodiazepine abuse among female outpatients in India. Addictive Behaviors, 18, 595-596.

Dhikav, V., Manaklata, P. and Anand, K. S. (2013). Medication adherence survey of drugs useful in prevention of dementia of Alzheimer's type among Indian patients. International Psychogeriatrics, 25, 1409-1413.

Glass, J., Lanctôt, K. L., Herrmann, N., Sproule, B. A. and Busto, U. E. (2005). Sedative hypnotics in older people with insomnia: meta-analysis of risks and benefits. BMF, 331(7526), 1169.

Satheesh, G. et al. (2020). Effects of sedative-hypnotics on sleep quality among patients with insomnia: evidence from an observational, pre-post study in India. Health and Quality of Life Outcomes, 18, 212.

Naranjo, C. A. et al. (1981). A method for estimating the probability of adverse drug reactions. Clinical Pharmacology E Therapeutics, 30, 239-245.

Reeve, E., Ong, M., Wu, A., Jansen, J., Petrovic, M. and Gnjidic, D. (2017). A systematic review of interventions to deprescribe benzodiazepines and other hypnotics among older people. European fournal of Clinical Pharmacology, 73, 927-935. https://doi.org/10.1007/s00228-017-2257-8

\author{
Vikas Dhikav, ${ }^{1}$ (D) Sangtitula Chang ${ }^{2}$ and \\ SONIA $\mathrm{MOR}^{3}$ \\ ${ }^{1}$ Scientist-D (Medical), ICMR-NIIRNCD, \\ \#1, Epidemiology Block, New Pali Road, Jodhpur, \\ Rajasthan 342005, India \\ ${ }^{2}$ Department of Neurology, Dr RML Hospital \& \\ PGIMER, New Delhi, India \\ ${ }^{3}$ Lingayas Vidyapeeth University, Faridabad, Haryana, \\ India
}

Correspondence should be addressed to: Vikas Dhikav, Scientist-D (Medical), ICMR-NIIRNCD, \#1, Epidemiology Block, New Pali Road, Jodhpur, Rajasthan 342005, India.

Phone: + 91 9717089307; 0291-2729716.

Email: dhikav.v@icmr.gov.in. 